\title{
Chromatic adaptation in the pigeon
}

\author{
JEAN ROBERTS ATAK and JOHN A. NEVIN \\ University of New Hampshire, Durham, New Hampshire
}

\begin{abstract}
This study presents evidence that adaptation to colored light alters the apparent hue of subsequently presented stimuli in pigeons. During training, right and left keypecks were reinforced following responses to colored and nominally achromatic slides, respectively. During test sessions, subjects continued to observe and report on the two classes of slides while 6-min components alternated, such that the experimental chamber was illuminated with either a green flood lamp or a nominally white bulb. The proportion of right keypecks following achromatic slides was much higher during green components than during white components, indicating that the achromatic slides appeared more like the chromatic slides.
\end{abstract}

In humans, prolonged exposure to a colored light (chromatic adaptation) has the effect of altering the appearance of subsequently presented stimuli. The latter stimuli may appear different in brightness, saturation, and/or hue (Hurvich \& Jameson, 1956; MacAdam, 1950). Following exposure to a green light, for example, a stimulus formerly appearing to be white or gray typically looks pink. Such chromatic aftereffects are often interpreted in terms of opponent processes in the visual system (Jameson \& Hurvich, 1972).

Various functional similarities between the vision of humans and that of pigeons have been demonstrated (e.g., see Wright, 1979, for a comparison of color vision in pigeons and humans). In addition, using single-cell recording techniques, Yazulla and Granda (1979) have identified neurons in certain structures of the pigeon visual system that have opponent-color characteristics. Thus, one might expect to find evidence for aftereffects of chromatic adaptation in the pigeon.

One sort of evidence for chromatic adaptation effects in the pigeon has been provided by the work of Graf and Norren (1974) and Norren (1975). In these studies, adaptation to various wavelengths of light altered the shape of the spectral sensitivity function, as measured by the electroretinogram (ERG) response. Further evidence, from studies that used suprathreshold stimuli, has been providèd by Williams (1974). Subjects were trained to peck a white key, with food reinforcement available only when the ambient illumination (provided by overhead lamps) was green. During training, the

This research was part of a PhD dissertation by J.R.A. and was supported in part by Central University Research Fund Grant S64, awarded by the University of New Hampshire. Reprints may be obtained from the first author, who is now at the Department of Psychology, Bucknell University, Lewisburg, Pennsylvania 17837. color of the overhead illumination was green, red, yellow, or white (white never followed red) and was changed every $30 \mathrm{sec}$. During subsequent test sessions, red preceded white illumination, and Williams found that response rates during white following red were elevated during the first $\mathbf{1 0} \mathrm{sec}$ of the interval. $\mathrm{He}$ interpreted this as evidence for negative afterimages $^{1}$ (one type of aftereffect of chromatic adaptation), with exposure to red light producing the subsequent experience of green during white illumination.

Other interpretations of Williams's (1974) results are possible, however. For example, novel stimulation has been reported to disinhibit responding under a wide variety of conditions, including extinction (e.g., Brimer, 1970). The red-white transition was a novel event and might therefore have occasioned a burst of responding during extinction quite apart from any induced aftereffects. Williams also reported progressive reduction of response rate to white after red as testing continued, which is consistent with the data on disinhibition. To preclude any alternative interpretation based on the general enhancement of responding, we assessed behavior indicative of the chromatic appearance of suprathreshold stimuli with a discrete-trial choice procedure. Pigeons were required to report on the appearance of localized stimuli (slides). If the slide was colored, a right keypeck was defined as correct and was occasionally reinforced, whereas if the slide was nominally achromatic, a left keypeck was correct. During test sessions, the ambient illumination was either intense green or nominal white, during alternating 6min intervals. If the birds experienced aftereffects of chromatic adaptation, the achromatic slides should have appeared colored during the green components. Indeed, it was found that the birds were much more likely to peck the right key following achromatic slides during green periods than during white periods. 


\section{METHOD}

\section{Subjects}

Four White Carneaux pigeons (Birds 23, 37, 40, and 230) served as the subjects. Birds 23 and 230 had experimental histories that included red-white discrimination, and Birds 37 and 40 had histories that included discriminative autoshaping, with colored CSs, and auditory discrimination.

\section{Apparatus}

The $30.5 \times 32 \times 35 \mathrm{~cm}$ experimental chamber illustrated in Figure 1 included three manipulanda: two standard pigeon keys positioned $18 \mathrm{~cm}$ apart and $20 \mathrm{~cm}$ above the floor, and, between them, a rectangular sleeve, $5 \times 5 \mathrm{~cm}$ at the opening and $12.5 \mathrm{~cm}$ long, into which the pigeon could insert its head. A back-projection screen was located at the end of the sleeve, and a photocell placed $3 \mathrm{~cm}$ beyond the sleeve opening allowed detection of the bird's head in the sleeve. A grain magazine was mounted directly below the opening to the sleeve and $5.5 \mathrm{~cm}$ from the floor. A houselight (nominal white) was pusitioned $4 \mathrm{~cm}$ above the sleeve opening. One of the walls of the experimental chamber, which served as a door and was constructed of clear Plexiglas, was covered with translucent tracing paper. Two sockets were mounted outside this wall; one socket held a green floodlamp (G.E. $100 \mathrm{~W}, 100$ PAR/G) or, in preliminary training, a standard white bulb, and the other held a white bulb (7.5 to $100 \mathrm{~W})$.

The above chamber was housed in a larger $60 \times 60 \times 90 \mathrm{~cm}$ insulated box equipped with a fan. An $8 \times 10.5 \mathrm{~cm}$ hole in the box allowed the beam from a Kodak Ektagraphic Carousel projector to enter a shutter positioned $9 \mathrm{~cm}$ behind the hole and $15.5 \mathrm{~cm}$ from the back-projection screen. A photocell was positioned at the level of the shutter so that the coded slides could be read as colored or achromatic. Control and recording equipment was in an adjacent room.

\section{Stimuli}

The stimuli consisted of a large pool of colored and black-andwhite slides, the former processed from Kodachrome film and the latter processed as direct positives from Kodak Panatomic-X film. In any given session, $\mathbf{4 0}$ slides of each type were presented one or more times, the order being block randomized, with no more than three in succession of either type. The slides used in early discrimination training consisted of various abstract patterns (grids, circles, triangles, letters, or no pattern) and were photographed over a three-f-stop range in order to vary the intensity or brightness of the slides. Colored slides were made either by photographing the patterns through one or more colored filters or by photographing colored cutouts on a white background or black or white cutouts on colored paper. Stimuli for two transfer tests involved (1) combinations of new and old colors with new and old patterns versus achromatic slides of new or old patterns and (2) photo-
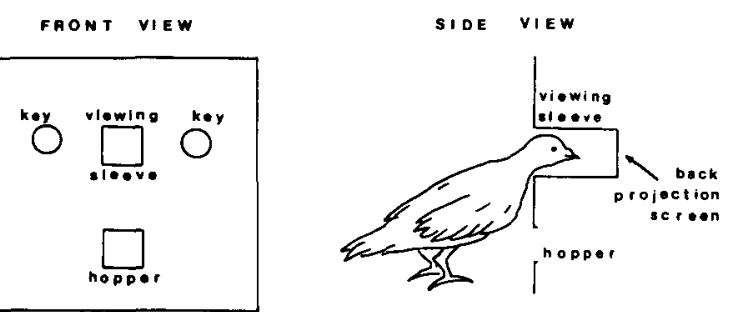

Figure 1. Schematic diagram (not to scale) of the control panel of the experimental chamber. The front view (left) shows the relative position of the response keys, viewing sleeve, and hopper. The side vlew (right) shows the location of the back-projection screen at the end of the viewing sleeve and the position required of the birds during a head-in. graphs of magazine pictures and paintings, both in color and in black and white.

A set of slides was selected from the pool employed in earlier work for use in the baseline and chromatic adaptation test sessions. The chromatic set included slides with fairly desaturated colors, including some with a light pink background such as might occur as an aftereffect of adaptation to green light. Different sets of slides was used in baseline and test sessions.

\section{Procedure}

Prellminary training. The birds were maintained at $80 \%$ of their free-feeding weights. They were trained first to peck a lit key, and then to insert their heads into the sleeve. Insertion of the head into the sleeve (a head-in) had the consequence of opening the shutter and, if the head remained within the sleeve for at least a specific amount of time, of closing the shutter and illuminating a side key. A single peck to the key extinguished the keylight and was reinforced with 4-sec access to grain. The head-in time requirement was gradually increased to $4 \mathrm{sec}$, and a 5 -sec blackout, in which the houselight was turned off and head-ins had no scheduled consequences, was added, contingent on short head-in times. A 5-sec intertrial interval with the houselight off was also added following each keypeck.

During the discrimination training that followed, both keys were lit when a successful head-in occurred, and only correct keypecks were reinforced. Correct responses were defined as right keypecks following presentation of a colored slide and left keypecks following presentation of an achromatic slide. The slide advanced during the intertrial interval whether the response had been correct or not. The set of chromatic stimuli originally included only red slides, but was gradually expanded to include red, green, orange, yellow, violet, and blue. The probability of reinforcement for correct responses was also gradually reduced to .45 . Two transfer tests, involving novel stimuli, were carried out next, with the same schedule of reinforcement in effect. After these tests, the birds experienced further training with additional slides, with occasional tests for a contingent chromatic aftereffect (Atak, Note 1).

Baseline sessions. With the above procedure still in effect, sessions were divided into eight 6-min intervals, during which one of the two lamps outside the chamber was illuminated. The two lamps (of different intensity, but both nominal white) were lit in alternation, and were extinguished whenever a pigeon had its head within the viewing sleeve. Because the birds' behavior was disrupted when these lights were introduced, dim lights were used for a time, with more intense lamps being gradually introduced. The final procedure employed 100 and $60 \mathrm{~W}$ white lamps.

Test sessions. Test sessions differed from baseline sessions in several ways. First, they included 10 6-min intervals. Second, the 100 -W white bulb was replaced by the green lamp or, in a control session, was simply removed. Finally, no reinforcement was available for responses following achromatic slides during the green (or dark) periods; that is, extinction was in effect for left-key responses during green. (Due to an apparatus failure, Bird 23 received no reinforcement for responses following achromatic stimuli in either component and had a total of 34 components in the first test session.) Four test sessions were carried out with the green flood lamp, with 11 to 15 baseline sessions intervening. One control session was then carried out as described above.

\section{RESULTS}

All four birds acquired the chromatic versus achromatic discrimination. Figure 2 summarizes the results of the transfer tests for each of the four birds, indicating the percentage of right keypecks following colored and achromatic slides during the first session in which the novel slides were presented. Note that a 
right keypeck is correct for colored slides and incorrect for achromatic slides. For the first transfer test, behavior following both new and old slides is indicated; only novel slides were included in the second transfer test. In the latter test, each slide was presented only once during the session. Clearly, the bird's discrimination behavior transferred to novel instances of the two stimulus classes, suggesting that a fairly general concept had been acquired (Keller \& Schoenfeld, 1950).

The results of the chromatic adaptation test and control sessions are shown in Figure 3. The percentage of right keypecks is shown for colored and achromatic stimuli during components with either green or white ambient light. A chromatic aftereffect should be manifested by a higher percentage of right responses following achromatic stimuli during the green components (unfilled triangles), as compared with that during white components (unfilled circles); that is exactly what has occurred for all birds. Bird 37 (and, to a lesser degree, Bird 40) also shows a higher proportion of right key responses when colored slides were presented during green components than when they were presented during white components, which might also be expected to result from chromatic adaptation: Many of the desaturated colored slides were pale pink, and these should appear even pinker following adaptation to green. (The percentage of right responses following colored stimuli is already near the maximum possible during white components for Birds 23 and 230. Even here, the same difference is exhibited in most test sessions.)

It should be noted that the reinforcement contingencies that were in effect during test sessions might also have been expected to lead to right keypecks following achromatic slides during green compo-

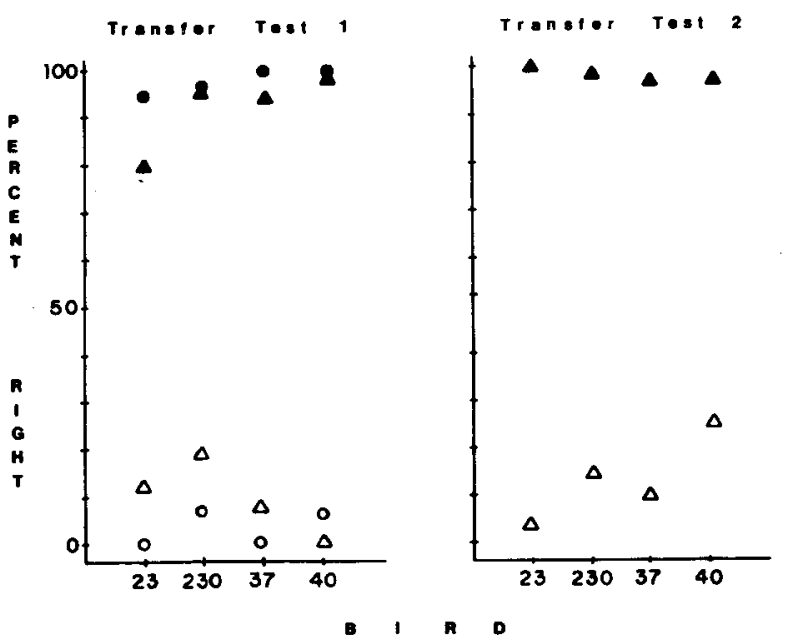

Figure 2. Percentage of right keypecks during the first session of each of Transfer Tests 1 and 2 for each of the four birds. Filled and open symbols are for colored and achromatic stimuli, respectively. Circles and triangles are for old and new slides, respectively.

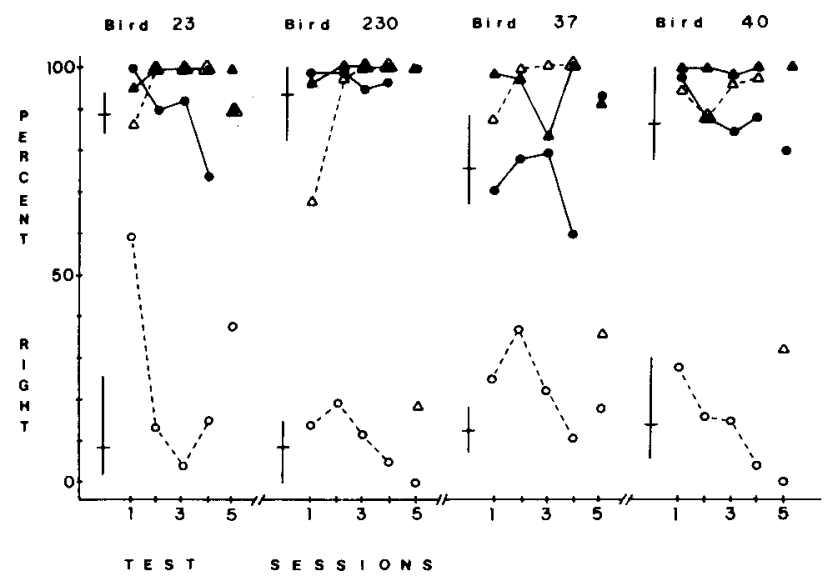

Figure 3. Percentage of right keypecks during chromatic adaptation test sessions and for the control session (Sesolon 5) for Birds 23, 230, 37, and 40 . Filled and open symbols are for colored and achromatic stimuli, respectively. Circles and triangles are for responses during white and green (or dark) components, respectively. Bars show the range and median performance during the baseline sessions prior to each test session for colored (above) and achromatic (below) stimuli.

nents. During these sessions, responses following achromatic slides during green were never reinforced; only right responses following colored slides were reinforced during green. It was felt that, since test sessions were infrequent and the rate of reinforcement was low, this change of contingencies was not likely to be discriminated by the birds. There is evidence, however, that such was not the case for at least two of the birds. First of all, an increase in percent right following both chromatic and achromatic slides during green is evident across test sessions for Birds 23 and 230 . This suggests that these birds gradually came to discriminate the change in contingencies and adopted a peck-right-during-green strategy. Birds 23's data during the first test session are also notable in showing an increase in the proportion of right keypecks following achromatic slides during white components: Due to an apparatus failure, this bird was never reinforced for left keypecks in either white or green components for this entire (usually long) session. Note, however, that the increase in right responses is greater during green than during white, suggesting that at least some of the increase during green was due to a chromatic aftereffect. The results of the control session show that all birds were able to discriminate the change in contingencies within a single session. Here, all birds showed more right responses following achromatic stimuli during the dark components (in which reinforcement was unavailable for left keypecks-unfilled triangles) than they did during white components (unfilled circles). Again, it should be noted that, except in the case of Bird 23, a much smaller percentage of right responses following 


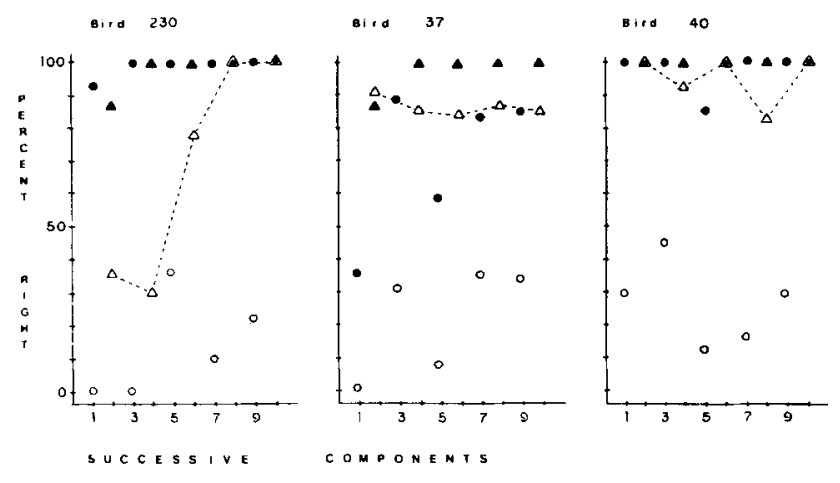

Figure 4. Percentage of right keypecks during successive 6-min components on the first test seasion for Birds 230,37 , and 40 . Filled symbols are for colored stimuli; open symbols are for achromatic stimull. Circles are for white (odd-numbered) components; triangles are for green (even-numbered) components.

achromatic stimuli occurred than was observed during green components for any of the previous test sessions. Thus, it seems that an aftereffect must also have contributed to the observed patterns of behavior, especially on the first test session.

The fact that both a chromatic aftereffect and the contingencies of reinforcement undoubtedly influenced the observed patterns of behavior makes it important to take a closer look at the data for the first test session, when the contribution from the reinforcement contingencies would have been at a minimum. Figure 4 shows the percentage of right responses during successive 6-min components for this session. (These data are not available for Bird 23.) We see here that all three birds clearly show a high proportion of right responses following achromatic stimuli during all colored components, including the very first one, which could hardly result from learning based on exposure to the test contingencies. However, a clear trend is evident starting in the third green component for Bird 230, which might be interpreted as the emergence of a new response strategy during green components. Evidently, performance during green components is the joint result of chromatic adaptation and test contingencies, at least for Bird 230 and, in view of the control data, for Bird 23.

\section{DISCUSSION}

This study provides additional evidence that aftereffects of chromatic adaptation occur in the pigeon, as they do in the human. Specifically, it shows that adaptation to colored light alters the perceived hue of subsequently presented stimuli, since black-and-white slides were much more likely to be reported as "colored" during those portions of the session in which the experimental chamber was flooded with green light.
Was the birds' behavior controlled by the appearance of the slides or by the color of the ambient illumination? For Birds 23 and 230, there is evidence that the latter was a factor, with the ambient illumination coming to serve as a cue signaling a change in reinforcement contingencies. Indeed, it is significant that these subjects seemed able to discriminate this change in contingencies within a single session, even though reinforcement was provided on a partial schedule. However, there is no evidence that the behavior of the other two birds came under the control of ambient illumination, at least during the first test session, and none of the birds' behavior patterns can be explained solely in terms of this type of stimulus control. It seems clear, then, that the appearance of the achromatic slides was indeed affected by the chromatic adaptation, and that this accounts for much of the increase in right keypecks during green components.

There certainly must be many differences between the perceptual worlds of pigeon and primate; indeed, several such differences have been demonstrated (e.g., Catania, 1964; Delius \& Emmerton, 1979; Kreithen, 1979; Wright, 1972; Wright \& Cumming, 1971). This study, however, demonstrates one additional functional similarity between the vision of these two species.

\section{REFERENCE NOTE}

1. Atak, J. R. Simple and contingent chromatic aftereffects in pigeons. Paper presented at the 52nd annual meeting of the Eastern Psychological Association, New York, April 1981.

\section{REFERENCES}

Brimer, C. J. Disinhibition of an operant response. Learning and Motivation, 1970, 1, 346-371.

Catania, A. C. On the visual acuity of the pigeon. Journal of the Experimental Analysis of Behavior, 1964, 7, 361-366.

Delius, J. D., \& Emmerton, J. Visual performance of pigeons. In A. M. Granda \& J. H. Maxwell (Eds.), Neural mechanisms of behavior in the pigeon. New York: Plenum Press, 1979.

Graf, V., \& Norhen, D. V. A blue sensitive mechanism in the pigeon retina: $\lambda \max 400 \mathrm{~nm}$. Vision Research, 1974, 14, 1203-1209.

HuRvich, L. M., \& JAMEson, D. Some quantitative aspects of an opponent colors theory. III. Changes in brightness, saturation and hue with chromatic adaptation. Journal of the Optical Society of America, 1956, 46, 405-415.

Jameson, D., \& Hurvich, L. M. Color adaptation: Sensitivity, contrast, after-images. In D. Jameson \& L. M. Hurvich (Eds.), Handbook of sensory physiology (Vol. 7). New York: SpringerVerlag, 1972.

Keller, F. S., \& Schoenfeld, W. N. Principles of psychology. New York: Appleton-Century-Crofts, 1950.

KrEIthen, M. L. The sensory world of the homing pigeon. In A. M. Granda \& J. H. Maxwell (Eds.), Neural mechanisms of behavior in the pigeon. New York: Plenum Press, 1979.

MacAdam, D. L. Loci of constant hue and brightness. Journal of the Optical Society of America, 1950, 40, 589-595.

Norren, D. V. Two short wavelength sensitive cone systems in pigeon, chicken and daw. Vision Research, 1975, 15, 1164-1166. 
Williams, J. L. Evidence of complementary afterimages in the pigeon. Journal of the Experimental Analysis of Behavior, 1974, $21,421-424$

Wright, A. A. The influence of ultraviolet radiation on the pigeon's color discrimination. Journal of the Experimental Analysis of Behavior, 1972, 17, 325-337.

Wright, A. A. Color-vision psychophysics: A comparison of pigeon and human. In A. M. Granda \& J. H. Maxwell (Eds.), Neural mechanisms of behavior in the pigeon. New York: Plenum Press, 1979.

Wright, A. A., \& Cumming, W. W. Color-naming functions for the pigeon. Journal of the Experimental Analysis of Behavior, $1971,15,7-17$.

Yazulla, S., \& Granda, A. M. Opponent-process units in the thalamus of the pigeon (Columba livia). Vision Research, 1973, $13,1555-1563$.

\section{NOTE}

1. We prefer to call this an aftereffect of chromatic adaptation. The term "afterimage" typically refers to aftereffects in which the adaptation stimulus is relatively small (requiring fixation) and/or brief (usually requiring a more intense stimulus).

(Manuscript received February 23, 1983; revision accepted for publication April 11, 1983.) 